УДК 004

\title{
ЗНАЧИМОСТЬ ИНФОРМАЦИОННЫХ ТЕХНОЛОГИЙ В ПОВЫШЕНИИ МОТИВАЦИИ СТУДЕНТОВ К ИЗУЧЕНИЮ ИНОСТРАННОГО ЯЗЫКА
}

\author{
Ковальчук Светлана Сергеевна \\ к. филол. н, доцент \\ Центр иностранных языков и \\ коммуникативных технологий, \\ Тюменский государственный университет
}

Аннотация: в данном исследовании изучено понятие мотивации и её видов, а также мотивы, которыми руководствуются студенты, изучающие иностранный язык. Установлено, что среди ведущих мотивов, побуждающих студентов к достижению положительного результата в учебно-познавательной деятельности выступают: мотив достижения, самоутверждения, идентификации, аффилиации и просоциальный мотивы. Рассматривая способы повышения мотивации к обучению, выявлено, что основополагающим способом в эпоху цифровизации является использования информационнокоммуникативных технологий. Владение иностранным языком и ориентация в информационных технологиях позволяют студентам стать конкурентоспособными на рынке труда в кротчайшие сроки после окончания учебного заведения. Применение информационных технологий вовлекает стимулирование и других способов мотивации: убеждение студентов в практической необходимости изучаемого, индивидуализация обучения, эмоциональное воздействие, проблемное обучение, вовлечение студентов в дискуссию. Результаты исследования показали, что дистанционный формат обучения диктует новые способы получения знаний и умений и эффективность процесса обучения напрямую зависит от владения навыками применения информационно-коммуникативных технологий как преподавателем, так и студентами. Студенты попали в среду, которая, так или иначе, мотивирует их к изучению информационных технологий. Мотивация обучающихся важнейший фактор, который обеспечивает эффективность образования. Информационные технологии сами по себе выступают достаточно сильным фактором, повышающим учебную мотивацию. Однако педагогически 
обоснованное их использование позволяет получить дополнительный мотивационный эффект.

Ключевые слова: мотивация, мотив, информационные технологии, информатизация, цифровая грамотность.

\title{
THE IMPORTANCE OF INFORMATION TECHNOLOGIES IN STUDENTS' MOTIVATION TO LEARN A FOREIGN LANGUAGE
}

\section{Kovalchuk Svetlana Sergeevna}

\begin{abstract}
: the present study aims at investigating the concept of motivation and its types, as well as the motives that students have when they study a foreign language. Among the key motives that encourage students to achieve a positive result in education and cognition are: the motive of achievement, self-affirmation, identification, affiliation and prosocial motives. Considering the ways to increase motivation for learning, it is revealed that the fundamental way in the digital world is the use of information and communication technologies. Knowledge of a foreign language and the ability to use information technology allow students to become competitive in the labor market in the shortest time after graduation. The use of information technologies involves the stimulation of other methods of motivation: convincing students of the practical necessity to study, individualization of learning, emotional impact, problem-based learning, involving students into discussion. The results of the study showed that the distance learning dictates new ways to acquire knowledge and skills, and the effectiveness of the learning process directly depends on the proficiency in the use of information and communication technologies by teachers and students. Students have found themselves in an environment that, in one way or another, motivates them to study information technology. The motivation of students is the most important factor that ensures the effectiveness of education. Information technologies are quite a strong factor that increases educational motivation. However, pedagogically justified use of them allows you to get an additional motivational effect.
\end{abstract}

Key words: motivation, motive, information technology, informatization, digital literacy. 
Изучением проблемы мотивации в разное время занимались многие учёные: Д.Б. Эльконин, В.В. Давыдов, Л.И. Божович, А.К. Маркова, Т.А. Матис, А.Б. Орлов и многие другие.

Согласно словарю Педагогическое образование под мотивацией понимается совокупность стойких мотивов, побуждений, определяющих содержание, направленность и характер деятельности личности, ее поведения [1].

Мотивация учения формируется под влиянием всей системы педагогических воздействий, но прежде всего она воспитывается в процессе непосредственной учебной деятельности. Воспитание положительной мотивации зависит от содержания обучения, организации учебного процесса, личности преподавателя.

В Толковом словаре Ушакова мотивация рассматривается как система доводов, аргументов в пользу чего-нибудь. С психологической точки зрения, мотивация - это совокупность мотивов, обусловливающих тот или иной поступок [2].

В Толковом переводоведческом словаре приводится следующее определение мотивации - потребность в том или ином поступке, в той или иной деятельности; система побудительных причин человеческого поведения, источник активности, организующий и направляющий деятельность человека [3].

При обучении иностранному языку выделяют несколько видов мотивации, составляющих в целом учебную мотивацию. К факторам, определяющим учебную мотивацию можно отнести следующие:

- особенности обучающегося (пол, самооценка, уровень интеллектуального развития);

- особенности преподавателя и его отношения к педагогической деятельности;

- организация педагогического процесса;

- специфика учебного предмета (в нашем случае иностранного языка)

В соответствии с факторами учебной мотивации ее можно подразделить на внешнюю и внутреннюю.

Внешняя мотивация не связана непосредственно с содержанием предмета, а обусловлена внешними обстоятельствами. Внешняя мотивация студентов может характеризоваться наличием определенных мотивов. В 
Толковом словаре Ожегова под мотивом рассматривается побудительная причина, повод к какому-либо действию [4].

Среди ведущих мотивов учебной мотивации в процессе обучения выступают:

- Мотив достижения - вызван стремлением студента достигать успехов и высоких результатов в изучении иностранного языка (получение отличных оценок, диплома и т. д.).

- Мотив самоутверждения - стремление утвердить себя, получить одобрение других людей. Многие студенты учат иностранный язык, чтобы получить определенный статус в обществе.

- Мотив идентификации - стремление студента быть похожим на другого человека, а также быть ближе к своим кумирам и героям (к примеру, с целью понимания текстов песен любимой группы).

- Мотив аффилиации - стремление к общению с другими людьми. Студент может учить иностранный язык, чтобы общаться с друзьямииностранцами.

- Мотив саморазвития - стремление к самоусовершенствованию. Иностранный язык служит средством для духовного обогащения и общего развития студента.

- Просоциальный мотив связан с осознанием общественного значения деятельности. Студент изучает иностранный язык, потому что осознает социальную значимость учения.

Внутренняя мотивация связана не с внешними обстоятельствами, а непосредственно с самим предметом. Её еще часто называют процессуальной мотивацией. Студенту нравится непосредственно иностранный язык, нравится проявлять свою интеллектуальную активность. Действие внешних мотивов (престижа, самоутверждения, и т.д.) может усиливать внутреннюю мотивацию, но они не имеют непосредственного отношения к содержанию и процессу деятельности.

Кроме того, учебную мотивацию можно разделить на положительную и отрицательную. К примеру, конструкция «если, я буду учить английский, то получу на экзамене отлично» - это положительная мотивация. Конструкция «если я буду учить английский, то сдам экзамен и меня не отчислят» отрицательная [5].

Безусловно, перспективы развития личности студента связаны с формированием положительной мотивации и совокупности перечисленных 101 
мотивов к изучению иностранного языка. Мотивация студентов при изучении иностранного языка позволяет добиться высоких результатов в приобретении новых и закреплении имеющихся знаний и навыков. Соответственно, студенты получают возможности для участия в конкурсах и программах международного обмена, в студенческих проектных работах и грантах; появляются перспективы быстрого карьерного роста, коллаборации со студентами других стран в процессе обучения и в будущем в их профессиональной деятельности. При этом ключевая роль всех этих перспектив отводится современным информационным технологиям, позволяющим легко и просто коммуницировать со «всеми и везде» [6].

В качестве ведущих способов повышения мотивации к обучению выступают в данном исследовании предоставление максимальной свободы студентам в выборе форм выполнения индивидуальной самостоятельной работы, тем доклада или вариантов решения практических задач. Студенты получают возможность ощутить свою сопричастность к образовательному процессу, осознать, что их точка зрения принимается во внимание.

Одним из способов повышения мотивации является проявление преподавателем интереса к личному опыту студентов в обсуждении каких-либо вопросов, совместное решение возникающих проблем. Организация дискуссий и рассмотрение ситуационных задач являются важными методами не только организации учебного процесса, но и налаживания качественных коммуникаций между преподавателем и студентом.

Преподаватель имеет возможность мотивировать студентов личным примером использования информационно-коммуникативных технологий при организации учебно-познавательного процесса, побуждая студентов также активно использовать достижения в сфере информационных технологий. $\mathrm{He}$ просто наблюдается объяснение материала, а приводятся примеры практического применения теоретических знаний (например, использование интерактивных возможностей Jalinga студии).

Для стимулирования мотивации студентов также необходимо отмечать их успехи и демонстрировать достижения студентов. В этом плане дистанционное обучение, при котором можно легко поделиться экраном и показать результаты работы, идеально подходит для описания достоинств и отличительных особенностей выполненной работы. В группе обычно собираются студенты разных поведенческих типов и, если экстравертам, людям с открытым общительным характером, обращённым в своих переживаниях и интересах к 
объектам внешнего мира (согласно Oxford Languages), достаточно просто взаимодействовать с социумом, то для интровертов это взаимодействие вызывает существенные сложности, особенно в случае проектных работ на английском языке. Однако, осознание того, что студенты группы видят работу студента, а не его самого, когда он делится экраном, к примеру, в Microsoft Teams или Zoom, прибавляет студенту уверенности в себе, повышает его внутреннюю мотивацию и желание снова достигать аналогичного результата, со временем его повышая.

Следует отметить, что в основном изучением вопросов, связанных с мотивацией учения, занимались в отношении к обучающимся школьного возраста. Вопросы мотивации студентов исследовались учеными в меньшей степени. М.А. Крылова называет следующие способы мотивации студентов к обучению: правильное целеполагание, убеждение студентов в практической необходимости изучаемого, индивидуализация обучения, эмоциональное воздействие, экскурсы в историю предмета, проблемное обучение, вовлечение студентов в дискуссию и др. [7]. В развитии мотивации личности студента важную роль играют мотивы, связанные с будущей профессиональной деятельностью.

Формирование у студентов мотивации к обучению будет реализовано в необходимом объеме только при условии наличия у учащегося интереса к учебной деятельности за счет использования определенных стимулов к обучению [8].

Информатизация современной жизни свидетельствует о том, что необходимо использование таких стимулов в процессе обучения студентов, которые помогут достаточно быстро адаптироваться к запросам рынка труда в ближайшем будущем. Выпускники Вузов должны владеть, как минимум, одним иностранным языком и хорошо ориентироваться в информационных технологиях, без которых, как показали события, невозможен успешный процесс обучения. Информационные технологии способствуют активизации и эффективному использованию информационных ресурсов (научные знания, открытия, опыт), позволяющих существенно экономить время, энергию людских ресурсов, а в условиях пандемии, способствуют улучшению показателей эпидемиологического благополучия, поскольку, находясь на дистанционном обучении, преподаватели и студенты меньше подвергаются опасностям окружающего мира. 
Определенно развитие цивилизации происходит в направлении становления информационного общества, в котором объектами и результатами труда большинства занятого населения являются информация и научные знания.

Значимость информационных технологий проявляется в информационном взаимодействии между людьми, а также в способах подготовки и распространения массовой информации. В социальной сфере широко используются системы электронных телекоммуникаций, электронная почта, факсимильная передача информации, системы электронного документооборота и другие виды связи. Студенты активно используют современные профессиональные базы данных и информационные справочные системы: интернет, доступ в информационно-образовательную среду университета, включающую в себя доступ к учебным планам и рабочим программам, к изданиям электронной библиотечной системы и электронным образовательным ресурсам, систему Modeus, офисное программное обеспечение (MS Excell, MS Visio, MS Power Point или аналоги); использование электронной почты преподавателей и обучающихся для рассылки, электроннобиблиотечная система elibrary, Единое окно доступа к образовательным ресурсам, КиберЛенинка, лицензионное программное обеспечение MS Office, MS teams, Moodle (elearning.utmn.ru) и многие другие ресурсы, которые приобрели особую важность и значимость при дистанционном обучении.

Поскольку в данном исследование рассматривается значимость информационных технологий в формировании мотивации студентов в процессе изучения иностранного языка, то особое значение придается изучению содержания обучения и организации учебного процесса с использованием современных информационно-коммуникативных технологий. Рассматривается какими навыками обладают студенты и какие приобретают при использовании информационных технологий, какие способы и методы осуществления поиска, сбора, хранения, обработки и распространения информации являются ключевыми для студентов современной цифровой реальности.

Информационные технологии занимают сегодня центральное место в процессе интеллектуализации общества, развития его системы образования и культуры. Во всем мире компьютерная техника и мультимедийные технологии становятся привычными атрибутами не только высших учебных заведений, но и обычных школ системы начального и среднего образования. 
Принципиально важное значение информационных технологий в развитии современного общества заключается в том, что их использование может оказать существенное содействие в решении глобальных проблем человечества, связанных с необходимостью преодоления переживаемого мировым сообществом глобального кризиса цивилизации. Методы информационного моделирования глобальных процессов, особенно в сочетании с методами космического информационного мониторинга, во многом обеспечивают возможность прогнозирования кризисных ситуаций в регионах повышенной социальной и политической напряженности, а также в районах экологических бедствий, в местах природных катастроф и крупных технологических аварий, представляющих повышенную опасность для общества [9].

Существует мнение о том, что применение информационных технологий в процессе обучения студентов наиболее актуально для направлений и специальностей в сфере информационных технологий. Однако, как показывают данные исследования, студенты разных институтов заинтересованы в приобретении знаний в данной области. За основу исследования был взят элективный курс «Информационные технологии в межкультурной коммуникации». Поскольку студенты разных направлений и специальностей могут выбирать данный курс, то по результатам выбора можно говорить о том, что контингент обучающихся, интересующихся информационными технологиями, разнообразен. Отмечаются следующие направления подготовки студентов, выбирающих данный курс: педагогическое образование, химия, информационная безопасность, прикладная информатика, журналистика, математическое обеспечение и администрирование информационных систем, психология, экономика, техническая физика, мехатроника и робототехника, математика и лингвистика. 50\% обучающихся на курсе составляют студенты Института математики и компьютерных наук, однако интерес студентов других институтов к изучению курса с использованием информационных технологий растёт. Безусловно, одним из ключевых факторов такой заинтересованности в настоящее время является получение знаний и навыков в дистанционном формате. Студенты реально осознают потребность в знании новейших информационно-коммуникативных технологий, с помощью которых они могут продемонстрировать имеющийся потенциал знаний и арсенал навыков. Студенты, возможно, сами того не желая, попали в такую среду, которая мотивирует их к изучению информационных технологий. Мотивация 105 
обучающихся - важнейший фактор, который обеспечивает эффективность образования. Максимальную пользу от обучения получают студенты с более высокими показателями мотивации. Информационные технологии уже сами по себе выступают достаточно сильным фактором, повышающим учебную мотивацию. Однако педагогически обоснованное их использование позволяет получить дополнительный мотивационный эффект.

Целью элективного курса «Информационные технологии в межкультурной коммуникации» является формирование и развитие у учащихся навыков уверенной разговорной речи профессиональной коммуникации на английском языке. При этом использование информационных технологий в процессе обучения выступает ключевым способом получения знаний на английском языке, их систематизации и активном применении в образовательном процессе не только в рамках данного курса, но и в других областях учебно-познавательной деятельности.

К основным задачам курса относятся:

- улучшение навыков понимания разговорной речи носителей на слух (беседа, монолог, информационные сообщения), включая восприятие речи, передаваемой через мультимедийные источники;

- расширение активного (применяемого) словарного запаса, также владение идиоматическими выражениями, включая фразовые глаголы в сфере высоких технологий;

- владение речевым этикетом повседневного общения и в области информационных технологий;

- овладение навыками заполнения анкет и регистрационных форм, деловой переписки, ведения переговоров;

- совершенствования уровня английского языка студентов в киберпространстве.

Элективный курс состоит из таких тем, как: online services, portable computers, computer networks, computer viruses, computers in education, robotics, virtual reality, multimedia, artificial intelligence, computer graphics и другие.

Элективный курс способствует приобретению практических навыков эффективного применения различного типа информационных технологий в повседневном и профессиональном контекстах. В процессе обучения студенты учатся находить ответы на такие вопросы, как: перспективы развития информационно-коммуникативных технологий, возможности существования современного общества без информационных технологий, взаимовлияние 106 
человека и информационных технологий, роль искусственного интеллекта, робототехники, виртуальной реальности в обучении и повседневной жизни.

Учебные встречи созданы как мероприятия, ориентированные на непосредственное и активное участие в них студентов. В результате учебных встреч наблюдается преодоление отчужденности участников образовательного процесса, обыденности, повседневности образовательной деятельности. Создаются условия для активного, мотивированного включения обучающихся в учебно-познавательную деятельность, приобретения практических компетенций. К примеру, студенты учатся анализировать опасность компьютерных вирусов, изучают возможности предотвращения их пагубного воздействия, создают тематические видео, интерактивные изображения, открытки с использованием Canva, PowToon, Prezi, Adobe Spark, Storify.com, StoryMapJS.com, Screencast-o-matic.com, Thinglink.com и других сервисов для графического дизайна, проектируют ситуации применения искусственного интеллекта, виртуальной реальности, робототехники, дополненной реальности в образовательном процессе и в повседневной жизни. Студенты активно используют современные сетевые сервисы в учебных проектах, что является дополнительной возможностью повысить мотивацию студентов к получению новых и закреплению имеющихся знаний и навыков. Использование сетевых сервисов делает проекты более интересными и наглядными, а также предоставляет возможность организовать совместную деятельность, в ходе которой у участников проектов формируются критическое мышление, рефлексивные умения, толерантность, навыки коммуникационного взаимодействия, ответственность за результаты совместной деятельности.

Выполнение разнообразных упражнений (описание диаграмм, анализ вебсайтов, викторины, составление кроссвордов, интеллектуальные соревнования и т.д.) с использованием информационных технологий не только позволяет приобрести новые и закрепить имеющиеся знания и навыки студентов, а также способствует восполнению пробелов в цифровой грамотности студентов.

Цифровая грамотность - это способность использовать те возможности, которые открывает современное общество со всеми его технологиями, умение коммуницировать с людьми в новом социальном формате, и быть этичным и внимательными друг к другу. Цифровая грамотность охватывает широкий спектр навыков, от оценки достоверности веб-сайтов до создания и обмена медиаконтентом [10]. 
Цифровая трансформация общества и образования требует формирования и развития у студентов разнообразных навыков. Среди необходимых навыков можно выделить сетевое мышление студентов, отличительной чертой которого является информационно-коммуникативная активность студентов в соответствии с сетикетом. Согласно Энциклопедическому словарю сетевой этикет (сетикет, нетикет - netiquette) рассматривается как совокупность норм, правил, предписаний, рекомендаций, отражающих представления о должном поведении и процессе коммуникации людей в сети Интернет. Сетикет является частью традиций и культуры сетевого сообщества, а также подчеркивает социальный уровень информационной культуры современного человека [11].

Информационная грамотность (навыки поиска нужной информации для решения поставленных задач) необходима для студентов, живущих в цифровом мире. При этом следует подчеркнуть, что студенты не только приобретают новые знания на учебных встречах, но и самостоятельно используют многочисленные информационные ресурсы для подготовки к практическим занятиям. Анализируя учебно-познавательную деятельность студентов элективного курса можно отметить их навыки оперативного поиска нужной информации, их умение оценить, проанализировать достоверность данных и правильно использовать для решения сформулированных проблемных учебных ситуаций.

Креативная компетентность (навыки творческого и эффективного подхода в обработке информации) характеризует современного цифрового студента. Креативная компетентность студента в интерпретации Н.А.Тимофеевой, является интегральным многофакторным качеством личности, обусловливающим на профессиональной основе саморазвития собственных творческих способностей студентов. Это самостоятельное личностное образование, находящееся в сложных диалектических связях с профессиональной компетентностью, предполагающих возможность, как совпадения, так и расхождения с ней [12].

Выполняя предлагаемые задания, студенты становятся полноправными участниками процессов преобразования в цифровой среде и могут критически осмысливать цифровую информацию, логически формулировать собственные умозаключения по обсуждаемым вопросам. Сформированность цифровых компетенций дает возможность студентам стать востребованными в будущем на рынке труда и социализироваться в цифровом пространстве. 
Подводя итог всему вышесказанному, следует отметить, что цифровизация образования предполагает расширение значимости информационных технологий, являющихся эффективным средством саморазвития, самосовершенствования, самообразования и самореализации студентов. Применение информационных технологий в процессе обучения делает обучающегося центральной фигурой учебно-познавательной деятельности. Педагог не является основным источником информации, а занимает позицию наставника, организующего самостоятельную деятельность обучающихся и управляющего ею. Основная роль преподавателя заключается в постановке целей обучения и организации условий, необходимых для успешного решения образовательных задач. Используя информационные технологии на занятиях, преподаватель получает дополнительные возможности для поддержания и направления развития личности обучаемого, творческого поиска и организации совместной работы, следовательно, стимулирует мотивационную составляющую процесса обучения студентов, изучающих иностранный язык. Мотивированный студент готов к приобретению фундаментальных знаний и практических навыков, изучает предмет осознанно и ориентируется на эффективное применение полученных знаний и навыков. Использование информационных технологий позволяет преподавателю развивать необходимые навыки информационно-коммуникативной активности студентов, восполнять пробелы в цифровой и информационной грамотности, формировать креативную компетентность.

\section{Список литературы}

1. Педагогическое образование. Словарь по педагогике. URL: https:// textarchive.ru/c-1254424-pall.html (дата обращения: 25.12.20)

2. Толковый словарь Ушакова. URL: https://dic.academic.ru/ dic.nsf/ushakov/863858 (дата обращения: 05.01.21)

3. Толковый переводоведческий словарь. URL: http://www.endic.ru /translate/Motivacija-1789.html (дата обращения: 04.01.21)

4. Толковый словарь Ожегова. URL: http://www.endic.ru/ozhegov/ Motiv16233.html (дата обращения: 06.01.21)

5. Данилова О. А., Конова Д. В., Дукин Р. А. Роль мотивации в изучении иностранных языков. URL: https://study-english.info/article018.php (дата обращения: 27.12 .20 ) 
6. Пассов Е. И., Кузовлев В. П., Кузовлева Н. Е., Царькова В. Б. Мастерство и личность учителя. На примере деятельности учителя иностранного языка: учеб. пособие. Изд-е 2-е, испр., доп. М.: Флинта; Наука, 2001. 240 c.)

7. Крылова М.А. Способы мотивации учебной деятельности студентов вуза // Перспективы науки и образования. 2013. №3. С. 86-94.

8. Богун В.В., Юдин В.В., Батракова Л.Г., Поваренков Ю.П. Развитие мотивации студентов вузов при обучении математике с использованием информационно-коммуникационных технологий. URL: https://cyberleninka.ru/ article/n/razvitie-motivatsii-studentov-vuzov-pri-obuchenii-matematike-sispolzovaniem-informatsionno-kommunikatsionnyh-tehnologiy (дата обращения: 28.12.20)

9. Роль и значение информационных технологий. URL: https:// sites.google.com/site/nyeprofessiivitiinnovaciah/rol-i-znacenie-informacionnyhtehnologij (дата обращения: 25.12.20)

10. Кузьмина М.В. Формирование цифровой грамотности обучающихся: Методические рекомендации для работников образования в рамках реализации Федерального проекта «Цифровая образовательная среда» / Авт.-сост. М.В. Кузьмина и др. - Киров: ИРО Кировской области, 2019. - 47 с.

11. Психология общения. Энциклопедический словарь. URL: https:// communication_psychology.academic.ru/ (дата обращения: 05.01.21)

12. Тимофеева Н.А. Креативная компетентность в профессиональной подготовке студентов педагогического вуза. [Электронный ресурс] // Преемственность в образовании. 2012. №2(11). URL: http://journal. preemstvennost.ru/arkhiv/31-2012-god/2112012/tekhnologii-ot-detskogo-sadadovuza/276-kreativnaya-kompetentnost-v-professionalnoj-podgotovke-studentov-peda gogicheskogovuza (дата обращения 06.01.2021)

(C) С.С. Ковальчук, 2021 